\title{
Foucault y la historia de la escolarización: presupuestos teóricos y debates historiográficos
}

Foucault e a história da escolarização: pressupostos teóricos e debates historiográficos

Foucault and the history of schooling:

theoretical assumptions and historiographical debates

\author{
Inés Dussel \\ Departamento de Investigaciones Educativas del Centro de Investigación y Estudios Avanzados (México) \\ http://orcid.org/0000-0003-3983-3985 \\ idussel@gmail.com
}

\section{Resumen}

En Nietzsche, la genealogía y la historia, Foucault abogó por una historia que haga tajos en el conocimiento establecido y que resista la seducción de las narraciones de reconciliación o consoladoras. Sin embargo, la historiografía educativa tendió a adoptar algunas hipótesis, sobre todo la de la escuela como institución disciplinaria que se presenta en Vigilar y Castigar, que terminaron resultando posiciones cómodas y poco intempestivas, como abogaba Nietzsche. En este artículo propongo una relectura de los planteos foucaultianos sobre la historia de la escuela, y en especial de un trabajo de un autor pos-foucaultiano, Ian Hunter, que publicó en 1994 una obra original sobre la escolarización, así como los debates que suscitó este trabajo. Se busca analizar sus perspectivas historiográficas y sus aportes para una comprensión más rica sobre la emergencia y los efectos de la institución escolar.

Palabras clave: Michel Foucault. Historia de la educación. Genealogía. Escolarización. Ian Hunter. 


\begin{abstract}
In Nietzsche, genealogy and history, Foucault claimed for a history that would cut through historical knowledge and resist the seduction of consoling narratives. However, educational historiography tended to adopt some hypothesis, above all the disciplinarian reading of schooling that is purportedly presented in Surveillance and Punish, that ended in comfortable positions that lost their critical edge. In this article, I propose a re-reading of Foucault's approach to the history of schooling, and particularly an analysis of a post-Foucaultian intellectual, Ian Hunter, who published in 1994 a highly original work on schooling, along with the debates that this work spurred. I will seek to analyze their historiographical approach and their contributions to a richer understanding of the emergence and effects of schooling.
\end{abstract}

Keywords: Michel Foucault. History of education. Genealogy. Schooling. Ian Hunter.

\title{
Resumo
}

Em Nietzsche, a genealogia e a história, Foucault defendia uma história que faria cortes no conhecimento estabelecido e resistiria à sedução de narrativas de reconciliação ou de consolação. No entanto, a historiografia educacional tendia a adotar algumas hipóteses, especialmente a da escola como instituição disciplinar que é apresentada em Vigiar e Punir, o que resultou em posições confortáveis e com pouco fio crítico. Neste artigo proponho uma releitura das posições de Foucault sobre a história da escola, e especialmente de uma obra de um autor pós-foucaultiano, Ian Hunter, que publicou em 1994 um trabalho original sobre a escolaridade, bem como os debates que surgiram com este trabalho. O objetivo é analisar suas perspectivas historiográficas e suas contribuições para uma compreensão mais rica da emergência e dos efeitos da instituição escolar.

Palabras-chave: Michel Foucault. Historia da educação. Genealogia. Escolarização. Ian Hunter. 


\section{Introducción: una nota personal sobre leer a Foucault}

Escribir sobre la obra de Foucault implica, siempre, un gran desafío. Si él mismo peleó contra la institución de una autoridad en el nombre propio, y trató de impedir, tanto como pudo, que se pensara a su obra de manera homogénea o unitaria, no sorprende entonces que "las operaciones que implica el comentario" (Chartier, 1996: 15-16) sean especialmente difíciles en su caso. Prefirió considerarse como un pensador "nómade", listo para "lanzar contra su propio discurso -inevitablemente portador de orden- una palabra de desorden que mina lo asentado y la completitud, es decir, la clausura" (Artières et al, 2011: 945, 948). Foucault solía reírse cuando le señalaban la diferencia entre sus primeros trabajos y los más recientes: "En la vida y en el trabajo lo más interesante es convertirse en algo que no se era al principio" (Foucault, 1990: 141). Por eso mismo, quizás las obras más interesantes sobre su pensamiento son las que buscan reconstruir qué escenas del pensamiento organizaba en el vínculo entre los libros y los artículos y entrevistas. Esta mirada a lo fuera del libro (horslivre) lleva a analizar los textos periféricos porque eran el arenero donde producía sus libros y también la autocrítica sobre los trabajos anteriores (Artières et al, 2011; Castro, 2011, 2014); es una forma poderosa de acceder a un pensamiento vivo, en acción, y adentrarse en sus operaciones materiales y en sus diálogos siempre abiertos.

En mi caso, a esos desafíos se suman otros que quisiera introducir brevemente, sin ánimo de confesiones pero sí de enmarcar el texto que sigue. La invitación a escribir un artículo que vuelva a visitar el pensamiento de Michel Foucault desde la historia de la educación, a propósito de la cercanía de los 50 años de la publicación de su ensayo "Nietzsche, la genealogía y la historia", supone revisar trabajos anteriores donde discutí tanto la categoría de genealogía (Dussel, 2004) como la de sus efectos en el pensamiento educativo (Dussel, 2010, 2012, 2016). En esos textos, me planteé debatir con las investigaciones en historia de la educación que usan el término "genealogía" como moneda de cambio para inscribirse en tradiciones críticas, aunque no sean consistentes ni consecuentes con varios de los presupuestos epistémicos y metodológicos de la perspectiva foucaultiana; también busqué criticar la lectura lineal y superficial de la hipótesis disciplinaria sobre la escuela centrada en "Los cuerpos dóciles", el tercer apartado de Vigilar y Castigar (1995), que ignoran la descripción minuciosa y precisa que hace Foucault de las formas de operación de las tecnologías de poder -entre las que ubica a la escuela-. ${ }^{1}$ La gran pregunta de si hay algo nuevo por decir, pregunta recurrente para quienes tenemos algunas décadas de trabajo intelectual, cobra mayor importancia cuando el tema ya se visitó varias veces.

Con estos retos y este camino ya recorrido, en este texto propongo un acercarmiento al "efecto Foucault" (como lo llaman Burchell, Gordon y Miller, 1991) sobre la historiografía de la escolarización. Esta indagación no intenta rastrear de manera exhaustiva a los receptores de Foucault sino analizar el pensamiento de algunos pedagogos que "han hecho de Foucault su precursor" (Canavese, 2014: 266). En ese sentido, siguiendo a Chartier (1998), podría decirse que el nombre propio "Foucault", y su obra, es el camino para poder llegar a nuevas formulaciones en torno a una pregunta que me parece central en el contexto contemporáneo: qué es y cómo se produce la escuela en nuestras sociedades. Para desplegar esta pregunta

\footnotetext{
${ }^{1}$ Cito la crítica tal como la esbocé en 2012: "Uno de los ejemplos más claros de esta domesticación del pensamiento de Foucault son las lecturas predominantes sobre Vigilar y Castigar, que lo convierten en un texto sociológico plano que sólo se ocupa de describir cómo se reprime a los sujetos. Edgardo Castro, autor de un impresionante trabajo sobre el vocabulario de Foucault (2004a), desafía esta lectura: "Vigilar y Castigar no es un libro de sociología: no describe a una sociedad sino a un ideal" (Castro, 2004b). Algo similar dijo Foucault en una entrevista que le hicieron a poco tiempo de publicar el libro: "Si hubiera querido describir la vida real en las prisiones, no me hubiera ido hasta Bentham" (Foucault, 2003a:253). Inmediatamente agregó que suponer que los ideales no son parte de la realidad es tener una idea muy pobre de lo real, pero ciertamente no creía que, al escribir Vigilar y Castigar estaba produciendo una historia o una sociología de las prisiones o de la escuela.” (Dussel, 2012: 147-148).
} 
entre los "herederos" de Foucault, tomaré como una suerte de hilo de Ariadna la hipótesis provocadora de Ian Hunter (1994) sobre la escuela como tecnología improvisada de poder pastoral, un argumento que sigue un abordaje genealógico tanto por su mirada histórica como por la diversidad de espacios y actores que rastrea. Ese hilo será enriquecido por la lectura de los debates que esa hipótesis generó en el campo de los historiadores de la educación, sobre todo en el mundo anglosajón pero también con efectos en el campo educativo latinoamericano. Es otra manera de aproximarse a lo fuera-del-libro, a ese diálogo vivo de la obra foucaultiana con el pensamiento educativo.

Para ello, en el texto haré una reconstrucción breve sobre la aproximación foucaultiana a la historia de la escolarización; en segundo lugar, presentaré mi lectura del texto de Ian Hunter, que plantea una hipótesis todavía sugerente sobre la emergencia de la institución escolar, y en tercer lugar introduciré algunos debates que este trabajo suscitó entre historiadores y filósofos de la educación. En las conclusiones planteo líneas de trabajo posibles para seguir profundizando el diálogo con la obra foucaultiana desde la historia de la escolarización.

\section{La historia de la escuela en la perspectiva foucaultiana}

En primer lugar, ¿cómo estudió Foucault a la escuela? Su aproximación fue siempre política e histórica: su análisis se movía a través del develamiento de las redes de poder en su constitución histórica, es decir, sus transformaciones. Su forma de hacer historia fue ante todo genealógica, estrategia que devino de una posición radicalizada respecto al conocimiento histórico y a sus promesas de objetividad y neutralidad. La genealogía asumió un carácter de combate; la definió como una tarea gris y meticulosa que demanda una erudición sin pausa, una tarea ciclópea que tiene que conjuntar materiales heterogéneos (Foucault, 1980). Para Foucault, el saber debe hacer "tajos" si quiere constituirse, siguiendo a Nietzsche, en conocimiento intempestivo, y no someterse a la centralización disciplinaria. El trabajo académico es así al mismo tiempo una intervención política, que indaga si las cosas pueden ser de otro modo; la genealogía busca romper con la visión homogénea y unitaria del conocimiento, y sorprender con nuevas asociaciones entre elementos aparentemente dispares.

En relación con su modo de trabajo intelectual, el método de Foucault era el de moverse permanentemente, experimentando en nuevos campos y lecturas. Señalan sus contemporáneos que era un trabajador incansable en el archivo, convencido de que este permitía descentralizar el sistema jerárquico de la biblioteca y adentrarse en múltiples series de datos que podían tener contradicciones e inconsistencias. Señala el filósofo español Miguel Morey que Foucault quería "hacer perder la autoridad de la biblioteca en lo que tenía de proyecto único, unitario, de ordenación de la cultura. El archivo será precisamente aquello que aparece en el lugar de la biblioteca cuando ésta pierde autoridad sobre el sentido" (Morey, 2014:192). Sus lecturas cruzadas, sus asociaciones imprevistas entre fenómenos o cuerpos de pensamiento que hasta entonces habían permanecido desconectados, ayudaron a volver visibles muchos aspectos de la existencia social y cambiaron profundamente la teoría social en las décadas siguientes.

Foucault bien podría haber sido el autor de una frase que acuñó uno de sus buenos lectores en Alemania, el historiador de los medios Friedrich Kittler: "No puedo pensar en otro medio que la indagación histórica para prepararnos para el futuro" (2004: 244). Su problematización de lo social procedía siempre por una historización de las formas de pensar o abordar un cierto tópico. La historia se escribía para Foucault en ese trabajo que iba de leer a tomar notas y fichar, para luego reorganizar las fichas en torno a distintas preguntas. En los archivos, Foucault buscaba capturar una episteme a través del recorrido por textos diversos, con una pretensión de "leerlo todo" (Artières et al, 2011: 959). Tomando la idea barthesiana del "en-deçà du langage", un más acá de la lengua (contra la idea hermenéutica de buscar el 
sentido en el más allá del lenguaje), Foucault se interesó por un más-acá de la historia, una historia que pudiera pensarse por fuera de las categorías modernas del pensamiento histórico. Con esta mirada política del archivo y la biblioteca, Foucault es uno de los primeros que buscó sistemáticamente en los documentos las miradas excluidas, marginadas, y rastreó textos menores y reglamentos de instituciones cotidianas para volver a pensar en cómo se establecieron las fronteras de lo que se podía decir y hacer y cómo cristalizaron ciertas jerarquías de los discursos.

La escuela apareció claramente en su obra en Vigilar y Castigar, publicado por primera vez en 1975. Pero ya en El nacimiento de la clínica, de 1963, se hacía explícita su preocupación por la institucionalización de los saberes y las transformaciones epistémicas y políticas que ese proceso conllevaba (Bocquet, 2014). Su crítica radical de la institución escolar la ubicaba del lado de la centralización del poder y de la jerarquización de ciertas formas de saber que desposeían a buena parte de la población.

En esa crítica, Foucault insistió que el poder tanto reprime como produce, y que esa producción tenía efectos de subjetivación no siempre predecibles ni gobernables. Así, es importante notar que en Foucault no hay una visión simplista del desarrollo humano, una dualidad moralista de buenos y malos, y tampoco una perspectiva romántica de la naturaleza humana que, liberada de la maquinaria del poder, sería libre e igualitaria. En vez de colocarse en juez de los eventos sociales, Foucault buscó entender las "prácticas como dominios de análisis, aproximarse desde el ángulo de "lo que fue hecho" (Foucault, 2003c: 4). En este sentido, su análisis permite interrogar cómo se constituye eso que consideramos que es social, mirando a la materialidad de las interacciones entre cuerpos, discursos y distintas configuraciones institucionales.

Recuperando la idea de Artières y otros sobre lo 'fuera del libro', no habría que dejar de ver en sus señalamientos críticos sobre la institución escolar los ecos de Mayo del '68, todavía frescos en el escenario francés cuando Foucault publicó su obra. Cabe mencionar que, si bien Foucault no estaba en Francia al momento de la revuelta sino en Túnez, lo que le dio una distancia que hoy podríamos llamar poscolonial respecto a los sentidos del movimiento, al poco tiempo él fue un actor importante, aunque de paso breve, en la experiencia institucional de la Universidad de Vincennes, posteriormente convertida en Paris 8. Esa experiencia, todavía poco estudiada, buscó radicalizar los programas de estudio y los vínculos pedagógicos (Brunet et al, 1979); el trabajo de Foucault recupera, como lo hace explícito en varias entrevistas, un diálogo sostenido pero también en contrapunto con los debates pedagógicos y políticos en torno a la institución escolar, que muestra una desconfianza de las propuestas de liberación pedagógica y también un interés genuino en el poder productivo de la escuela.

La lectura de Foucault de la escuela en Vigilar y Castigar refiere a un momento en el que las distintas instituciones de la modernidad en los siglos XVII al XIX se estructuraron en base a estrategias e invenciones que buscaron producir ciertas subjetividades. Foucault planteó que en esa época surgieron nuevas problemáticas y lenguajes para responder a otros desafíos. Entre esas nuevas problemáticas estaba la de la disciplina, a la que él entendió antes que nada como una hipótesis de una dinámica que atravesaba varios campos heterogéneos. Su método partía de un corpus mixto, que combinaba reglamentos de corporaciones de artesanos, estatutos de escuelas parroquiales de 1660, manuales de las escuelas de los Hermanos Cristianos (Lasalle) de 1720-1750 y escuelas lancasterianas del 1800. Si bien se trata de experiencias educativas muy diferentes, la apuesta de Foucault de ponerlos juntos para ver qué permitían pensar sobre procesos más amplios fue tan interesante como audaz.

¿Cuál es el argumento central que plantea Foucault sobre la escuela como dispositivo del poder disciplinario? El primer objetivo de este poder era volver dóciles a los cuerpos, algo que no era nuevo pero que tenía características diferentes a las formas tradicionales de operación del poder. Para Foucault, las disciplinas cambian la escala del control: es un poder 
que requiere ser trabajado en sus partes, que se convierte en poder infinitesimal sobre el cuerpo activo. Cambia también el objeto del control: pasa a tener importancia la economía, la eficacia de los movimientos, el ejercicio continuo, y ya no la ceremonia y la performance de los cuerpos en la corte del rey; también se reconfigura la modalidad del control que se convierte en una coerción ininterrumpida, constante, con una codificación que reticula con la mayor aproximación el tiempo, el espacio y los movimientos.

Las escuelas aparecen como uno más de los espacios, junto con las cárceles, los hospitales y los cuarteles, atravesados por las disciplinas como unas "fórmulas generales de dominación", "métodos que permiten el control minucioso de las operaciones del cuerpo, que garantizan la sujeción constante de sus fuerzas y les imponen una relación de docilidadutilidad" (Foucault, 1995:141). Es importante señalar que Foucault hablaba de disciplinas en plural: reconocía que hay una especificidad de cada uno de los dominios (y de las técnicas) de las que no se ocupaba, porque le interesaba entenderlas en tanto fórmula general de dominación, como una táctica coherente. Es claro, entonces, que Foucault admitió que no proponía una lectura particular de lo escolar, sino una clave de análisis que lo relacionaba con otros fenómenos en curso en el momento de su emergencia.

Si el objetivo era producir cuerpos dóciles, sometidos y ejercitados, ese objetivo se desarrolló por medio de una retícula de instituciones y operaciones a las que llamó una "microfísica" (Foucault, 1995:153). Eso lo lleva a formular que "[1]a disciplina es una anatomía política del detalle" (Foucault, 1995:143): no sorprende entonces que las formas de encauzamiento de la conducta se alojasen en las meticulosidades de la pedagogía escolar, por ejemplo en el "Tratado de las obligaciones de los hermanos de las Escuelas Cristianas" de Lasalle al que llama su "gran himno a las cosas pequeñas". Podría decirse que en estas operaciones historiográficas de rescatar del olvido al tratado lasalleano, y darle carta de ciudadanía en la "gran historia" de la configuración de la política y la subjetividad, Foucault estaba dando un paso importante para dimensionar la relevancia de la acción escolar en las sociedades modernas. En otro párrafo, Foucault dio una definición del poder disciplinario muy sugerente: lo caracterizó como un poder modesto, suspicaz, que funcionaba según el modelo de una economía calculada pero permanente (idem). No era el poder majestuoso de los grandes soberanos o aparatos de estado; se basaba en "humildes modalidades, procedimientos menores. [...] Y son ellos precisamente los que van a invadir poco a poco esas formas mayores, a modificar sus mecanismos y a imponer sus procedimientos" (Foucault, 1995:175). Es un poder que va desde arriba hacia abajo, no en una forma vertical sino dendrítica, reticular.

Puede avanzarse un poco más en su análisis, para terminar de bosquejar el planteo foucaultiano sobre la escolarización. El encauzamiento de las conductas se realizó separando, analizando, diferenciando, llevando sus procedimientos de descomposición hasta las singularidades necesarias y suficientes. En este sentido, y como ya se señaló, es claro que el poder disciplinario produce, incita: "fabrica' individuos." (idem). Contra la idea liberal de que hay una naturaleza humana anterior que es reprimida por el poder, Foucault pone en evidencia que los individuos fueron producciones del poder disciplinario. Al respecto, Marcelo Caruso (2005), en una sugerente discusión sobre el análisis del poder disciplinario en la educación latinoamericana, proporcionó un buen ejemplo de sus características:

[La] visibilidad de una mano que toma un lápiz o de unos dedos que dan vuelta a una página son sólo posibles a partir de una condición casi invisible para estas elaboraciones temporales [del acto, evoluciones lineales que unen movimientos]: en las escuelas seriadas, en las escuelas donde se conforma un centro y un campo de visibilidad tanto para los docentes como para los alumnos, esta serialidad sólo se logra en tanto se 
logre tener sentados a los niños. La historia del banco escolar es así no sólo la historia de un mueble que produce nostalgias, sino la historia de la sedentarización de la infancia que posibilita las operaciones de enseñanza. [...] Sin sedentarización de la infancia, no es posible la "actividad" reglada, la actividad escolar. (Caruso, 2005:183)

La producción de la subjetividad no puede entenderse por fuera de esta imbricación de estrategias políticas, tecnologías materiales y organización discursiva-política del espacio y las identidades que contribuyeron a organizar el poder disciplinario en la escuela. Foucault especificó también algunos de los medios por los que este poder se hizo efectivo: "El éxito del poder disciplinario se debe sin duda al uso de instrumentos simples: la inspección jerárquica, la sanción normalizadora y su combinación en un procedimiento que le es específico: el examen" (Foucault, 1995:175).

Este análisis es probablemente el más conocido, y mal entendido, de la obra foucaultiana sobre la escuela. En una crítica reciente, François Dubet (2014) señaló la limitación de la perspectiva foucaultiana para entender la realidad escolar, que según él se parece más a una commedia dell'arte que a una tragedia antigua (p. 243). Pero la lectura de Dubet es bastante plana: se queda en la hipótesis maquínica o de sistema de engranajes de su obra, su costado más determinista o estructuralista, y plantea que desconsidera otras experiencias nacionales como la norteamericana donde el programa institucional asumió características distintas. Dubet rescata como una virtud del planteo de Foucault la continuidad de la hipótesis weberiana sobre la burocracia estatal, aunque no mantuvo el interés del sociólogo alemán por la dimensión simbólica de las instituciones; pero no le da ningún valor a la genealogía para interrumpir y hacer tajos en las formas de concebir la escuela, o a la apertura foucaultiana hacia el post-estructuralismo, particularmente en la atención que Foucault le prestó a las especificidades de los dominios y modos de operación del poder, que le dio mayor densidad y matices a la lectura de la institución escolar, y a la contingencia como principal dinámica en la historia.

Para concluir esta aproximación a la aproximación foucaultiana a la escuela, vale la pena recordar que otros estudiosos franceses de su obra destacan que Vigilar y Castigar no es la única obra en que el filósofo francés se ocupó de la escuela. Entre otras contribuciones, señalan el valor de la conceptualización de las heterotopías, los espacios otros, como lugares liminares que autorizan la palabra de otros y que actúa como una referencia que permite desvíos, sueños, mediaciones diferentes; la escuela sería un espacio-otro que opera creando posibilidades distintas para los discursos. Por otro lado, también subrayan la importancia de la noción de la parresia, es decir, el "decir la verdad", el ofrecer una experiencia del mundo, como constitutiva de la acción del profesor (Prairat, 2014; Karsenti, 2014). En estas dos líneas, se ofrece una perspectiva filosófico-política más amplia de la acción escolar que la hipótesis de la máquina disciplinaria, aunque no se propone una relectura historiográfica sobre la emergencia de la escuela, como sí lo hace el trabajo que se analiza a continuación.

\section{La hipótesis de Ian Hunter: la genealogía de una "institución improvisada"}

El texto de Ian Hunter, publicado en inglés en 1994, surgió de una invitación realizada por Meghan Morris, destacada crítica cultural australiana, para que Hunter produzca una lectura crítica de los debates educativos australianos a principios de la década de 1990. En 1998 el libro fue traducido al español y publicado en Barcelona por Editorial Pomares; un texto de Ian Hunter que resume el argumento central del libro fue publicado en portugués en la obra compilada por Tomaz Tadeu da Silva, Pedagogia dos Monstros-una magnífica recopilación de textos poco conocidos hasta entonces en el ámbito latinoamericano (Hunter, 2000). 
El libro se presentó como un ensayo escrito para presentar algunas ideas que permitieran ir más allá del debate entre conservadores y liberales, posiciones ambas 'principistas' que sostienen que la escuela es la expresión o desarrollo de un principio central, ya sea la conservación de la sociedad o la libertad individual Se identificó como heredero de las ideas foucaultianas y llamó a su propio trabajo una genealogía de la escuela (p. xvi), genealogía sin principios ('unprincipled', no basada en principios, como se la tradujo al español). La genealogía no quería buscar orígenes profundos sino quedarse en la superficie de la emergencia de lo escolar. Hunter definía así su proyecto intelectual:

[E]sta genealogía se concentra en las condiciones contingentes en las cuales el sistema escolar se convirtió en lo que es, y en las técnicas culturales, instituciones y modos de reflexiones disponibles desde los cuales se lo ensambló. La imagen resultante no es entonces la de la aparición de la escuela como la manifestación parcial de un principio subyacente, sino la de un ensamblaje improvisado como dispositivo para dar cauce a las contingencias de una historia particular. (Hunter, 1994:xvii)

Puede observarse en esta definición las huellas del texto de Foucault sobre Nietzsche, la genealogía y la historia: la noción de aparición o emergencia versus la de origen o causalidad, la búsqueda de los despliegues en la superficie, la noción de contingencia. Al mismo tiempo, es evidente una relación más distante con las hipótesis disciplinarias de Vigilar y Castigar, particularmente con la identificación de la escuela como máquina. El eje del análisis de Hunter se centró en las categorías de gobierno y subjetividad, que aparecieron en los trabajos tardíos de Foucault, sobre todo en una serie de conferencias sobre la gubernamentalidad y las tecnologías del yo pronunciadas entre 1979 y 1982 . Hunter señaló que "le debemos a Michel Foucault esta renovación del análisis del sujeto como un compartimiento histórica y culturalmente específico del individuo, que depende de técnicas o procedimientos de subjetivación especiales" (Hunter, 1994:34). El poder disciplinario estaba presente en su lectura de lo escolar, pero el foco central descansaba en la formación de individuos que podían relacionarse consigo mismo "como seres capaces de un trabajo ético, y que por lo tanto pueden comenzar ese 'trabajo del yo sobre el yo' que reconocemos como la persona reflexiva" (ídem).

Para Hunter, esto no se vincula tanto a la operación de una grilla disciplinaria como a la intensificación histórica de la pedagogía pastoral cristiana. El maestro como pastor es quien mejor puede llevar adelante el trabajo de subjetivación que propone la escuela de una persona moral que pueda comportarse como un burócrata, es decir, como un buen ciudadano que acepte ser gobernado y que realice un trabajo sobre sí mismo para conducirse correcta y moralmente en los términos en que define el Estado. Este maestro pastoral, a quien llamó el "maestro empático" (1994:10), debía combinar los saberes de un padre cuidadoso y un guía espiritual; por eso se diferenciaba tanto del tutor monitorial poco entrenado como del profesor de gramática muy especializado (1994:73). Esta observación indicaba también un distanciamiento de las hipótesis de Vigilar y Castigar, que identificaron las escuelas monitoriales lancasterianas con el modelo pedagógico triunfante de la instrucción pública, algo que los historiadores de la educación han rebatido desde hace tiempo (Querrien, 1979; Narodowski, 1995; Caruso, 2015). En varios sentidos, su trabajo historiográfico era algo más cuidadoso que el de Foucault en su consideración -si bien exigua- de la historiografía educativa y de algunas fuentes primarias sobre los períodos considerados, en especial para el siglo XIX inglés y prusiano y de las iniciativas en torno a las mediciones de la inteligencia en el siglo XX. Sin embargo, priorizó una lectura filosófico-política general sobre la escuela, en desmedro de aproximaciones más específicas a desarrollos o problemas que hubieran requerido mayores matices o detalles. $\mathrm{Su}$ 
lectura responde, de manera anticipada, a la crítica de Dubet de la ausencia de la dimensión simbólica en los planteos foucaultianos sobre la escuela: Hunter entró de lleno al problema de la constitución de los sujetos y los discursos de la escolarización.

Uno de los méritos claros del trabajo de Hunter es, a mi juicio, el énfasis en el carácter histórico de la construcción de la escuela, y de ahí su insistencia en el término "improvisado", que aparece repetidas veces a lo largo del texto. Así, puede leerse que "el sistema escolar es una institución altamente impura, tácticamente improvisada, ensamblada desde distintas esferas de vida y que sirve a una mezcla de lentes espirituales y mundanos" (1994:xxii). Más adelante se reafirma que la escuela es "el producto de un proceso de construcción institucional improvisado que consiguió enlazar un programa de formación social y un medio de disciplina espiritual" (1994:75). La improvisación, en este caso, es lo opuesto a la planificación o a una acción dirigida sistemáticamente por una voluntad unificada, y viene a resaltar que las creaciones políticas se despliegan en la contingencia. Hunter argumentó que la escuela se organizó institucionalmente con las técnicas, figuras y discursos que había disponible en su momento: el modelo burocrático de los estados nacionales emergentes, la mayor parte absolutistas, y las tecnologías pastorales de gobierno de las distintas iglesias cristianas, con un mayor peso de las luteranas y evangélicas por su relación con la cultura escrita y la individualización de la relación con Dios. Sostuvo que los sistemas escolares se parecen entre sí porque las opciones disponibles no eran muchas; la peregrinación a la Volkschule de Prusia era casi obligada a principios del siglo XIX, ya que era de las pocas experiencias que podían considerarse exitosas en una integración pedagógica de las demandas de gobierno social y gobierno individual.

Si en la consideración de los debates entre lancasterianos y pedagogos de la simultaneidad de la escuela prusiana Hunter se distancia de Vigilar y Castigar, en otros aspectos se aproxima al método de Foucault en ese texto seminal. Uno de esos aspectos es la consideración de la materialidad de lo escolar como concreción de las tácticas políticas, por ejemplo en la atención a los horarios y los movimientos de los cuerpos. En particular, Hunter rastreó la historia de espacios escolares como la galería -el aula con gradas típica de mediados del siglo XIX que focaliza la atención en el maestro y que le permite a éste seguir con la mirada la acción de todos los alumnos- y el patio, a los que consideró como la "corporización arquitectónica y la secularización de la pedagogía pastoral cristiana” (1994: 73).

Al patio escolar le dedicó varias páginas, dándole una mayor importancia políticopedagógica que a la distribución de las aulas como celda o "huevera" (egg crate), que suele ser vista como la mejor expresión del poder panóptico (Fernández Enguita, 2017). Hunter rastreó las propuestas pedagógicas de los movimientos cartistas en Inglaterra en los escritos de William Lovett y John Collins, y de los reformadores "de clase media" (así los llamó) que trabajaron como inspectores o formadores de maestros -como David Stow y James KayShuttleworth-. Si bien ambos sectores estaban enfrentados respecto a la autoridad del estado para dictaminar programas o credencializar a los maestros, en relación al patio escolar los dos grupos se ponían de acuerdo: era un espacio privilegiado para la educación porque permitía una "libertad supervisada", un trabajo sobre la verdadera naturaleza de la infancia que más que instruir debía incitar y observar, "guiar por la influencia moral y no tanto por la física", modelo que se extendería a la intervención estatal sobre la educación popular (1994:xiii-xiv).

El objetivo del patio escolar era que los niños jugaran libremente pero con un adulto supervisando sus interacciones. La libertad sería "una condición de una nueva y más íntima forma de vigilancia moral" (1994:9), y de ninguna manera se opone al gobierno sino que es más bien su condición. Los docentes "empáticos" debían guiar la consciencia, y no ser coercitivos; en la escena activa o ocupada del patio, el educador debe hacerse presente para "estimular la alegría juvenil". Hunter incluyó varias citas del trabajo de David Stow, The Training System, the Moral Training School, and the Normal Seminary (1850), entre ellas una en la que queda claro el tipo de trabajo moral que debe realizar el maestro pastoral: "[t]odo es 
libre como el aire, y sujeto sólo a una observación moral de cualquier delincuencia particular, cuya revisión se reserva para la galería escolar, y retomada una vez que los niños retornen allí, y planteada como una lección moral formativa" (Stow, citado por Hunter, 1994:10).

El trabajo de Hunter terminaba en una crítica furibunda al intelectual crítico, al que consideraba el representante excelso de la subjetividad gubernamental-estatal y por lo tanto poco apto para producir una lectura radical de la escuela y su inscripción en la producción de la libertad regulada. Al mismo tiempo, señalaba la ceguera de estas tradiciones intelectuales respecto a las formas de operación escolares, sus tecnologías y disposiciones espaciales y corporales, a las que se veía como secundarias respecto a los principios ideológicos de individualidad racional o democracia social que supuestamente debían realizar los sistemas educativos. Esta crítica le valió una cierta marginalización de la historiografía educativa, como se verá en los debates que se reseñan en la próxima sección.

\section{La recepción de "Repensar la escuela": algunos debates historiográficos}

Al poco tiempo de la publicación del libro de Hunter, la revista Australian Educational Researcher organizó un dossier especial de debate sobre sus argumentos, en el que participaron el filósofo de la educación norteamericano Cleo Cherryholmes y los historiadores Colin Symes y Lyn Yates, ambos con larga tradición en la investigación educativa australiana. Este debate, poco conocido en el mundo hispanoparlante, muestra algunas repercusiones interesantes de sus postulados entre historiadores y filósofos de la escuela, y señalan posibilidades y límites de las lecturas foucaultianas sobre la historia de la escolarización.

En primer lugar, las tres resenciones confluyeron en la importancia de la contingencia en la historia, y en ese sentido destacaron el aporte de Hunter para una historización atenta a las combinaciones azarosas de las fuerzas o dinámicas existentes. Resaltaron también su importancia para considerar el peso de las tradiciones pastorales de auto-examen y regulación de la libertad, argumentos que "hay que tomar muy en serio" (Yates, 1995:125). Pero los acuerdos terminaron en ese punto. Cherryholmes fue quien más valoró el libro, al que consideró "una contribución importante a los discursos y prácticas que continuamente reconstituyen" la historia del sistema escolar (Cherryholmes, 1995:114), y quizás un presagio de cambios en curso. Señaló que es un argumento "bien colocado, bien formulado, y que se demoró en llegar" (p. 110), aunque creía que no tendría buena recepción, al menos en el corto plazo, sobre todo entre los profesionales de la educación a los que cuestionaba desde sus principios y efectos. Sus críticas se dirigieron hacia las (pocas) alternativas que Hunter dejó disponibles ante el desmantelamiento de la figura del intelectual crítico y del fundamento en principios para propuestas como la democracia o la justicia escolares; sugirió volcarse más claramente al pragmatismo, por ejemplo de John Dewey, a quien consideró buen complemento de la obra de Foucault, y elaborar un pensamiento post-fundacional que se centrase en los efectos de la experiencia estética de la escolarización como criterio que sustituya a los principios político-filosóficos existentes.

Las críticas de Yates y Symes se involucraron, más abiertamente que Cherryholmes, con las hipótesis históricas sobre la escuela, a las que consideraron exageradas y esquemáticas. En el caso de Yates, formuló una crítica -que podría calificarse de furiosa, casi en espejo con la de Hunter sobre el intelectual crítico- contra el estilo del libro, al que acusó de replicar la posición del intelectual masculino que enuncia la gran teoría y no necesita pruebas -evidencia de lo cual son las pocas referencias a la historiografía educativa en el libro de Hunter. Esa crítica también alcanzó a su método, que para ella no procedía de manera suficientemente rigurosa con las fuentes y priorizaba un argumento teórico por sobre el estudio minucioso de procesos que tienen muchos matices e inconsistencias. La hipótesis teórica sobre la escuela fue vista a la vez como un valor (asumiendo el riesgo de enunciar una postura) y una debilidad; Symes comparó 
el libro a las películas de Quentin Tarantino, que "conmueven o shockean la sensibilidad y por eso dejan una impresión indeleble" (Symes, 1995:118).

Hay dos direcciones en estas críticas que valdría la pena retomar y repensar a la luz de otros debates recientes sobre la historia de la escuela. En primer lugar, Yates y Symes acusaron a Hunter de destronar a los intelectuales y pedagogos y poner en su lugar a los burócratas educativos, que se convirtieron en el nuevo "genio de la botella" (Symes) o "héroe" (Yates) del cambio educativo. Así, el libro de Hunter presume que David Stow es quien desarrolló "el tejido técnico de la pedagogía contemporánea y quien comprendió que (...) el comportamiento moral y ético de los niños de clase obrera podría ser reconstruido para atemperar los excesos de la educación callejera" (Symes, 1995:116117). Yates lo acusó de no tener en cuenta los movimientos sociales ni a otros actores no estatales que tuvieron también impacto en la escolarización. También discutieron su desprecio por los intelectuales educativos, ya sean de derecha o izquierda, negando que algunos de ellos ampliaron los campos discursivos y permitieron la emergencia de posturas críticas, incluida la del propio Hunter.

La respuesta de Hunter, matizada y respetuosa, fue destacar que su intención no era reemplazar un héroe con otro sino "expandir el alcance del concepto del intelectual para incluir a 'intelectuales administrativos' y, de manera más fundamental, quitarle el aura postkantiana, como el vehículo por el cual la razón entra a la política y la historia" (Hunter, 1995:128). Defendió haber considerado a los movimientos sociales, pero analizados desde el punto de vista de su moralidad y sus supuestos político-pedagógicos, y no desde su posición en un campo de lucha preestablecido. También sostuvo la importancia de prestarle atención a las "tecnologías intelectuales y políticas" y las circunstancias en que se las usa. Su discusión de estas tecnologías "intenta no distribuirlas entre héroes y villanos morales sino enfatizar su autonomía técnica, la contingencia de sus interacciones, y su subsecuente indeterminación ética y política" (Hunter, 1995:128).

Este es un aspecto en el que Hunter parece haber anticipado el trabajo de los historiadores materiales de la escuela, y en ese sentido habría que darle la razón a Cherryholmes de la condición de presagio o augurio de su texto de otros cambios epistémicos y materiales en curso. Las técnicas y el espacio escolares tienen, en el argumento de Hunter, un margen de acción (una capacidad de actantes, para decirlo en los términos de Bruno Latour, 2005), que hasta ese momento no se les había otorgado. Este sigue siendo un aporte destacable del argumento de Hunter.

La segunda dirección de la crítica de Yates y Symes es sobre la consideración de la especificidad de los procesos históricos. Symes criticó la ausencia del salón de clase, del aula, en el estudio de Hunter, y más en general la evacuación de toda sustancia en la forma escolar. Por ejemplo, en relación a las disciplinas y conocimientos escolares, Symes cuestionó que se las considerara igualmente volcadas al trabajo sobre sí -por medio del examen de tono confesional-, sin distinguir entre las humanidades, donde eso es más frecuente, y las ciencias experimentales, que tienen formas de trabajo más epistemológicas que existenciales. También discutió su perspectiva centrada en los sistemas educativos occidentales, sin considerar qué excluyeron y qué fracasos o discriminaciones educativas provoca esta exclusión; para Symes la hipótesis de Hunter estaba "podada" de estas aristas conflictivas o discriminatorias. Yates, por su parte, reclamó que el argumento no le hizo lugar a diferentes desarrollos históricos, buscando entender, entre otros ejemplos, por qué en ciertos países la educación privada fue más importante que la pública, o cuál fue la relación entre las luchas políticas por la igualdad de género o social y las razones burocráticas, que obligaron a cambios políticos trascendentes en las décadas de 1960 y 1970. En su opinión, el argumento generalizante sobre la escuela, impulsado por la teoría foucaultiana "de moda", impedía a Hunter considerar la complejidad e inconsistencia de muchos de los procesos que pretendía explicar. Más aún, incluyó ese 
argumento en las formas de enunciación del patriarcado, que pueden realizar afirmaciones universales sin dar cuenta del propio lugar de enunciación.

La respuesta de Hunter fue la de invitar a nuevos trabajos que amplíen o corrijan su lectura de algunos procesos específicos, pero sostuvo su argumento central de la "improvisación histórica" de la escuela como tecnología, es decir, su carácter de ensamblado de fuerzas históricas contingentes y múltiples en el cual las minucias y los detalles técnicos y materiales jugaron un rol fundamental. Reiteró, bastante fiel a Foucault, que la escuela no tenía un principio moral bueno o malo, ni su desarrollo un sentido de progreso necesario; la decisión que tomó era la de dirigir su investigación hacia las situaciones históricas que permitieron la emergencia de la escuela moderna, y en ese sentido afirmó la modestia de la teoría para proveer algunas claves de interpretación o líneas de investigación pero no una dirección para la acción política.

\section{A modo de conclusión: ¿qué aportan los foucaultianos a una teoría de la historia de la escuela?}

La revisión de los planteamientos foucaultianos sobre la historia de la escolarización y de sus repercusiones posteriores en el trabajo de Ian Hunter, así como de los debates críticos que suscitó, buscó indagar algunas posibilidades y límites que abrió esta línea de trabajo en relación a la historia de la escolarización. Como se señaló al inicio del artículo, este trabajo no pretende ser un trabajo exhaustivo de todos los seguidores de Foucault en la historia de la educación, sino una lectura de algunos textos que, tomando el nombre propio "Foucault", produjeron teoría sobre la historia escolar.

¿Cuáles son las posibilidades que produjeron estas intervenciones foucaultianas en el pensamiento histórico-educativo? Una primera cuestión que puede señalarse es que esos aportes no se restringen a la hipótesis disciplinaria de Vigilar y Castigar, que, aún con sus inmensas contribuciones, corre efectivamente el riesgo de convertirse, sobre todo en la vulgata de divulgación, en una hipótesis determinista y esquemática. Pero esa vulgata maquínica no le hace justicia a esta obra; analizada más de cerca, Vigilar y Castigar abona a una comprensión de lo escolar desde claves de lectura política que siguen siendo relevantes, por ejemplo en su identificación y descripción de las escalas y modalidades del control o de las técnicas de ejercicio del poder, cuyo contenido podría actualizarse a formas nuevas como los portafolios de auto-evaluación o las narraciones de la propia práctica en la formación docente. Esta mirada minuciosa sobre la imbricación de lo político en las formas institucionales amplió considerablemente la historia de la escolarización.

Una segunda cuestión es la atención a la materialidad de las operaciones de poder, sus tecnologías y artefactos, su trabajo sobre los cuerpos, que es una línea que ha abierto indagaciones muy fértiles en la historia escolar. Esto llevó a Ian Hunter a estudiar la acción de los inspectores o formadores de docentes que imaginaron rutinas y espacios específicos para las prácticas escolares, otorgándoles a estas últimas "carta de ciudadanía" como objetos legítimos de indagación académica. Si bien esa atención no es exclusiva de los foucaultianos, no hay duda que esta línea contribuyó mucho al avance del "giro material" en la historia de la educación, y a desplazar a las intenciones o los dichos de los actores humanos del centro de las preocupaciones historiográficas.

Una tercera cuestión es una mirada renovada a la constitución de las subjetividades, ya no desde las producciones textuales - a nivel de las ideologías- sino en la escala de la configuración cotidiana de la trama de discursos y cuerpos en la que los sujetos se constituyen. El trabajo de Hunter tuvo el valor de proponer como objeto la formación de un sujeto ético a través de las prácticas de auto-examen y de conversación sobre el dominio moral de la conducta en las escuelas. Su análisis fue más allá de una crítica superficial de la 
ideología y atravesó campos epistemológicos y posiciones políticas diferentes; encontró más líneas de continuidad que de ruptura entre actores que aparecían contradictorios. Si eso es, en la visión de Yates, algo que hace perder especificidad y matices al análisis histórico, sin embargo no deja de señalar que en esas confluencias hay un nudo problemático de la formación de la subjetividad en la modernidad.

Por el lado de las limitaciones de esta aproximación, es cierto, como afirman los críticos al texto de Hunter, que las hipótesis teóricas con pretensiones de gran escala corren el riesgo de dejar de lado las inconsistencias y particularidades de distintos desarrollos o eventos históricos. En el caso que se analizó, el argumento de que la escuela es una improvisación histórica de fuerzas contingentes y múltiples, con todo lo importante que resultó para abrir un programa de investigación sobre esa contingencia, no da muchas pistas de cuáles fueron esas fuerzas y cómo se ensamblaron; en su celebración del pluralismo, tampoco apunta a fortalecer el análisis de los distintos tipos de combinaciones que se dieron en distintas configuraciones espacio-temporales, o a desplegar su carácter precario, siempre en riesgo de des-ensamblarse (Dussel, 2017). También puede señalarse que la hipótesis de alto nivel de generalidad no le hace lugar a la consideración del trabajo específicamente pedagógico de las escuelas, por ejemplo ciertas operaciones con los textos que podemos llamar estudio, o ciertas formas de convivencia o de construcción de un espacio común (Simons y Masschelein, 2014).

Para finalizar quisiera volver al comienzo de este artículo, cuando hablé de mi intención de revisar los aportes foucaultianos en torno a una pregunta que considero central para nuestras sociedades: qué es y cómo se produce la escuela. A través de este recorrido, quise mostrar que sus contribuciones no son solamente enunciados particulares que dan respuesta a esta pregunta, sino sobre todo la formulación de modos o estrategias de plantearse los interrogantes, que optan teóricamente por la multiplicidad y la contingencia. La teoría de la historia de la escolarización, entonces, sería menos un conjunto de afirmaciones definidas de una vez y para siempre, que una serie de presupuestos conceptuales y metodológicos sobre cómo aproximarse a un objeto de estudio, y que sólo puede hacerse "poco a poco, a partir de una reflexión (necesariamente histórica, en alguna de sus dimensiones) sobre situaciones dadas" (Foucault, citado en Morey, 2014:177); una teoría modesta, local, pero con grandes posibilidades de abrir líneas de indagación ricas y originales sobre las condiciones de emergencia de la escuela y las circunstancias de sus transformaciones.

\section{Referencias}

Artières, P., J.-F. Bert, P. Michon, M. Potte-Bonneville \& J. Revel (2011). Dans l'atelier de Michel Foucault. In Ch. Jacob (dir.). Lieux de savoir 2. Les mains de l'intellect. Paris. Albin Michel, pp. 944-962.

Bocquet, K. (2014). Assujettissement et désassujettissement: l'enseignement dans le jeu des pouvoirs. In E. Prairat (ed.), À l'école de Foucault. Nancy: Presses Universitaires de Nancy, pp. 69-90.

Brunet, J., Cassen, B., Châtelet, F., Merlin, P., Reberioux, M. (1979). Vincennes ou le désir d'apprendre. Vincennes: Éditions Alain Moreau.

Burchell, G., C. Gordon y P. Miller (Comp) (1991). The Foucault Effect. Studies in Governmentality. Chicago: The University of Chicago Press.

Canavese, M. (2014). La recepción temprana de Foucault en Argentina. De los '50 a la radicalización política. Nuevo Mundo Mundos Nuevos, 34. https://doi.org/10.4000/nuevomundo.66295 
Caruso, M. (2005). “'Sus hábitos medio disciplinados': enseñanza, disciplina y disciplinamiento en América Latina", en: Zuluaga, O. y otros, Foucault, la Pedagogía y la Educación. Pensar de otro modo. Bogotá, Universidad Pedagógica Nacional, Cooperativa Editorial Magisterio, pp. 163-200.

Caruso, M. (ed.) (2015). Classroom Struggle: Organizing Elementary School Teaching in the 19th Century. Frankfurt am Main: Peter Lang.

Castro, E. (2011) Lecturas Foucaultianas. Una historia conceptual de la biopolítica. Gonnet: UNIPE-Editorial Universitaria.

Castro, E. (2014). Introducción a Foucault. Buenos Aires: Siglo XXI Editores.

Chartier, R. (1996). Escribir las prácticas. Buenos Aires: Manantial.

Chartier, R. (1998).Why the Linguistic Approach Can Be an Obstacle to the Further Development of Historical Knowledge. A Reply to Gareth Stedman Jones. History Workshop Journal, No. 46 (Autumn), pp. 271-272.

Cherryholmes, C. (1995). Rethinking the School with the Help of Michel Foucault. Australian Educational Researcher, 22(1), 107-114

Dubet, F. (2014) Foucault et l'école: une absence d'usage. In Hervé Oulc'hen (ed.), Usages de Foucault. Paris: PUF, p. 231-250.

Dussel, I. ( 2017). Sobre a precariedade da escola. In J. Larrosa (ed.), Elógio da Escola. Belo Horizonte: Autêntica Editora, pp. 87-111.

Dussel, I. (2016). El «efecto Foucault» en educación: Notas sobre los usos, malas lecturas y relecturas de un pensamiento. In Langer, E. y B. Buenaventura (eds.), Usos y prospectivas de Foucault a 30 años de su muerte. Buenos Aires: Editorial Del Gato Gris/Universidad Nacional de San Martín/Universidad Nacional de la Patagonia Austral, pp. 21-33.

Dussel, I. (2012). La disciplina y el poder en la escuela: Una lectura desde Foucault. In Furlán, A. (comp.), Reflexiones sobre la violencia en las escuelas. México D.F.: Siglo XXI, pp. 144-174.

Dussel, I. (2010). Foucault and Education. In Apple, M., S. J. Ball \& L.A. Gandin (eds), The Routledge International Handbook of the Sociology of Education. London \& New York: Routledge, pp. 27-36.

Dussel, I. (2004). Foucault y la escritura de la historia: Reflexiones sobre los usos de la genealogía. Educaçao e Realidade, 29 (1), 45-68.

Fernández Enguita, M. (2017). Más escuela y menos aula. Madrid: Ediciones Morata.

Foucault, M. (1980). Nietzsche, la Genealogía, la Historia. En: Microfísica del Poder. Madrid: La Piqueta. 
Foucault, M. (1990, e.o. 1982). "Verdad, individuo y poder", en Tecnologías del yo (selección y edición de Miguel Morey). Barcelona: Paidós.

Foucault, M. (1995) Vigilar y castigar, el nacimiento de la prisión. México: Siglo XXI.

Foucault, M. (2003). Michel Foucault. Maurice Florence. In P. Rabinow and N. Rose (ed.), The Essential Foucault. Selections from The Essential Works of Foucault, 1954-1984. New York: The New Press, pp. 1-5.

Hunter, I. (1994). Rethinking the School. Subjectivity, Bureaucracy, Criticism. New York: St. Martin's Press. [traducción al español: Repensar la escuela. Subjetividad, burocracia, crítica. Barcelona: Ed. Pomares, 1998].

Hunter, I. (1995). Response to Cherryholmes, Symes, and Yates. Australian Educational Researcher, 22(1), 126-129.

Hunter, I. (2000). Subjetividade e goberno. In: T.T. da Silva (ed.). Pedagogía dos monstros. Os prazeres e os perigos da confusao de fronteiras. Belo Horizonte: Autêntica, pp. 141-163.

Karsenti, B. (2014). Foucault et la parole de vérité des modernes. In Hervé Oulc'hen (ed.), Usages de Foucault. Paris: PUF, 319-334.

Kittler, F. (2004). Universities: Wet, Hard, Soft, and Harder. Critical Inquiry, 31(1), 244 -255. https://doi.org/10.1086/427310

Latour, B. (2005). Reassembling the social. An introduction to Actor-Network-Theory. ford, UK: Oxford University Press.

Morey, M. (2014). Escritos sobre Foucault. México DF: Sexto Piso.

Narodowski, M. (1995). Infancia y poder. La conformación de la pedagogía moderna. Buenos Aires: Aique editorial.

Prairat, E. (2014). Introduction. Foucault, penseur de l'éducation. In E. Prairat (ed.), À l'école de Foucault. Nancy : Presses Universitaires de Nancy, pp. 5-14.

Querrien, A. (1979). Trabajos elementales sobre la escuela primaria. Madrid: Ediciones de la Piqueta.

Simons, M. y J. Masschelein (2014). En defensa de la escuela: Una cuestión pública. Buenos Aires: Miño y Dávila.

Symes, C. (1995). Rethinking the School: Genie-logy or Genealogy? Australian Educational Researcher, 22(1), 115-118.

Yates, L. (1995). Not Rethinking the Grand Intellectual. Australian Educational Researcher, 22(1), 119-125. 